\author{
Assistant Professor Fatine Maghrebi, PhD \\ E-mail: mfatine@kku.edu.sa \\ King Khaled University, Abha, Kingdom of Saudi Arabia \\ Associate Professor Zouaoui Chikr El Mezouar, PhD \\ E-mail: zchikrelmezouar@kku.edu.sa \\ King Khaled University, Abha, Kingdom of Saudi Arabia \\ Assistant Professor Ibrahim Almanjahie, PhD \\ E-mail: imalmanjahi@kku.edu.sa \\ King Khaled University, Abha, Kingdom of Saudi Arabia
}

\title{
TEST OF CAUSALITY BETWEEN OIL PRICES AND GDP CASE STUDY SAUDI ARABIA
}

Abstract: This paper examines the causal relationship between oil prices and the effects of real Gross Domestic Product [GDP] in the Kingdom of Saudi Arabia [KSA] based on a data set collected over a period from 1998 to 2014. We seek how change in real crude oil price affects the GDP of KSA positively. Based on an empirical study analysis of the time series characteristics of the data (stationarity) using the Augmented DickeyFuller [ADF] test, our results confirm numbers of cointegration between oil price and GDP which lead to run the pairwise Granger causality test. We show that the two series are of order one integrated, that there are two cointegration relationships between Oil prices and GDP, and pairwise causality between these two variables. All the statistical analyses are performed using Eviews software.

Keywords: Time series, Stationarity, ADF, Co-integration, Causality, Granger Test.

\section{Introduction}

KSA is the 14th largest country in the world (around 2 million square kilometers) and is the second largest OPEC (Organization of the Petroleum Exporting Countries) country member. The country is the largest exporter of petroleum and possesses about 18 per cent of the world's petroleum reserves. The Saudi Arabian oil and gas sector accounts for 50 per cent of GDP, and 85 per cent of export earnings. Therefore, an increase in oil price increases economic growth. The importance of this research lies in determining the causal relationship between these two variables to see who is the dependent variable and who is the independent variable.

DOI: 10.24818/18423264/52.3.18.19 
Fatine Maghrebi, Zouaoui Chikr El Mezouar, Ibrahim Almanjahie

There are three main objectives for this research. The first one is to investigate the relationship between the GDP of KSA and the oil prices and to verify if the two variables have the same order of integration (order of stationarity) using Unit Root tests. The second objective is to discuss if there exist a co-integration between the two variables(the GDP of KSA and the oil prices). Final objective will deal with finding the sense of causality using Granger test.

The rest of the paper is organized as follows. Section 2 deals with literature review. In Section 3, we present the real data and the background theory that related to the test of causality (unit root test, co-integration test and Granger test).Section 4 shows numerical results of the relationship between the variables, the GDP of KSA and the oil prices and Section 5 gives the conclusion of this work.

\section{Literature Review}

There have been many empirical studies on the relationship between economic growth and oil price in the last decades. Hamilton (Hamilton, 1983) highlighted a negative relationship between oil prices and macroeconomic activity in the United States. Later, Mork (Mork, 1989), Lee and al. (Lee and al, 1995) and Hamilton (Hamilton, 1996) used nonlinear transformations into the models and Granger causality tests. Their results confirmed the negative relationship between oil price fluctuations and slow-down in economic activity as well as Granger causality from oil prices to economic growth before 1973 but no Granger causality from 1973 to 1994; see also Federer (Federer, 1996), Hamilton (Hamilton, 1997), Lee and $\mathrm{Ni}$ (Lee and Ni, 2002). In another study, Hooker (Hooker, 1996) shows that from 1948 to 1972, oil price variability has influence on GDP growth. More recently, Gounder and Barleet (Gounder and Barleet, 2007) showed a direct link between net oil price shock and economic growth in New Zealand. In addition, they proved that oil price shock has substantial effect on inflation and exchange rate.

Jin (Jin, 2008), comparing Japan, China and Russia, showed that oil price increases has a negative impact on economic growth in Japan and China and a positive impact on economic growth of Russia. In (Elmezouar and al, 2014) Elmezouar and al discussed the causality between the GDP and oil price in Algeria. 
Test of Causality between Oil Prices and GDP. Case Study Saudi Arabia

None of the previous studies have discussed the casual relationship between the GDP and the oil prices in KSA. In this project we will investigate such relationship based on a real data collected from reliable resources in Saudi Arabia.

\section{Data and Methodology}

\subsection{Data and variables}

The variables that we used in our application are the real GDP and the oil price. Figure 1 shows the evolution of real GDP and oil price in Saudi Arabia from 1998 to 2014. The real GDP is characterized by an upward trend while the price of oil is presented as an additive model. We found that the correlation between the real GDP and oil price equals 0.90 which means that there exists a strong positive relationship between the two variables. However, it should be noted the continuing rise in oil prices since 1998. This increase was due to continuing political factors and other cyclical order.

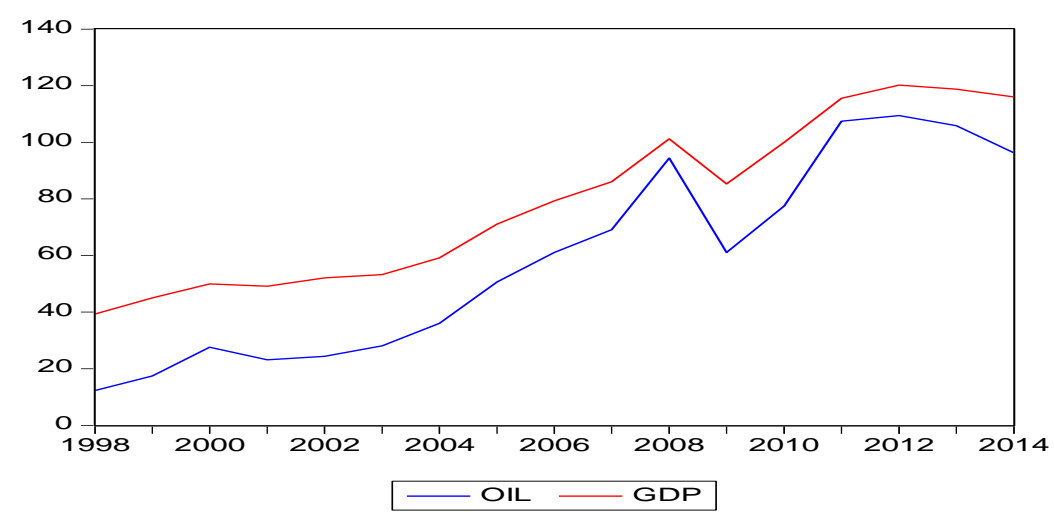

Figure 1: Oil and GDP in KSA from 1998 to 2014

Data Source: (Saudi Arabian Monetary Authority, 2016)

DOI: 10.24818/18423264/52.3.18.19 
Fatine Maghrebi, Zouaoui Chikr El Mezouar, Ibrahim Almanjahie

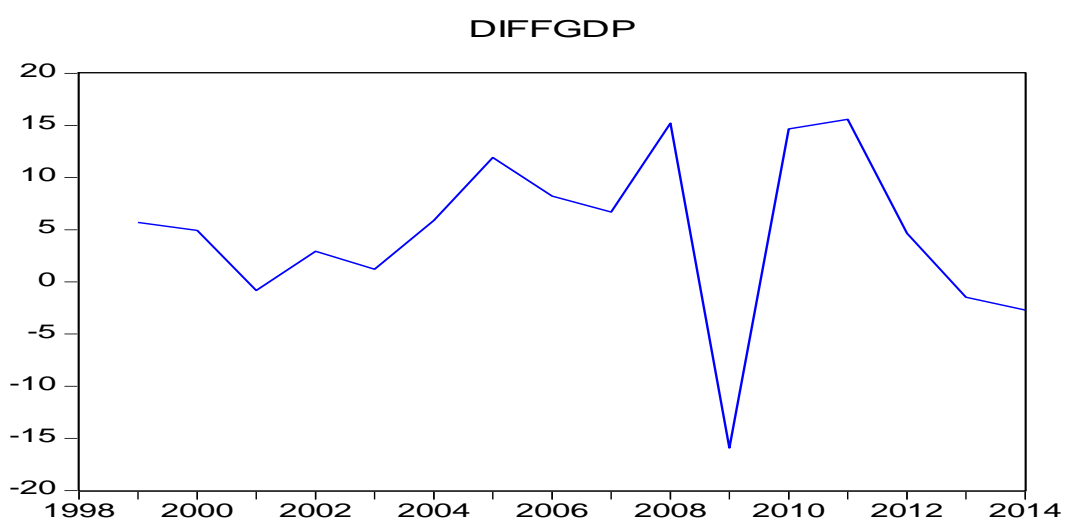

Figure 2: Difference of GDP

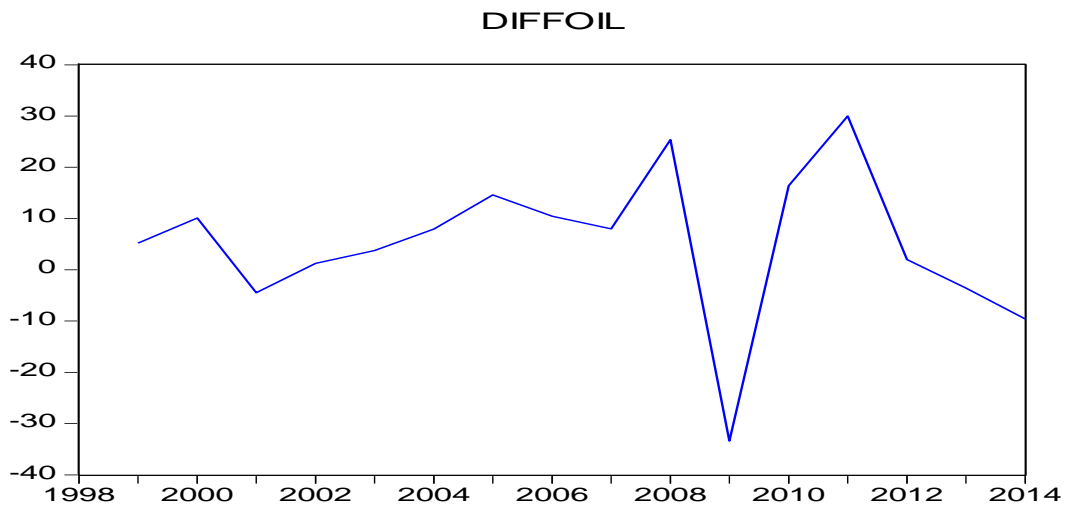

Figure 3: Difference of oil price.

We can see from Figure 1 that, the inflation-adjusted price of a barrel of crude oil from the 1998 to 2000 was generally under US $\$ 25 /$ barrel. During 2000 to 2001, the price decreased and then increased till 2008.Commentators attributed these price increases to many factors, including Middle East tension, soaring demand from China, the falling value of the U.S. dollar. From 2008 to 2010, the oil price decreased and then increased again after 2010 till 2014. We note that the curve of GDP takes the same path as the oil price curve, and the GDP shape also follows the same behavior as the oil price. We think that there exists a cointegration between oil price and GDP. 


\subsection{Unit Root Test:}

Many economic series have non-stationary behavior, however, the series of differences $\Delta y_{t}=y_{t}-y_{t-1}$ is often stationary and we say then that $y_{t}$ is a first order integrated series or simply $I(1)$.Unit root tests allow to examine the order of integration. In this study, we use the ADF test (Dickey and Fuller, 1981), (Dickey and Fuller, 1996) to examine whether a series has a unit root. Consider the ADF tests as follows:

$$
\begin{aligned}
& \Delta y_{t}=\varphi y_{t-1}+\sum_{i=1}^{p-1} \beta_{i} \Delta y_{t-i}+\varepsilon_{t} \\
& \Delta y_{t}=\alpha_{0}+\varphi y_{t-1}+\sum_{i=1}^{p-1} \beta_{i} \Delta y_{t-i}+\varepsilon_{t} \\
& \Delta y_{t}=\alpha_{0}+\alpha_{1} t+\varphi y_{t-1}+\sum_{i=1}^{p-1} \beta_{i} \Delta y_{t-i}+\varepsilon_{t}
\end{aligned}
$$

It should be clear that equation (1) does not include either drift nor trend, while the drift term $\alpha_{0}$ is added to equation (2) and both the drift term $\alpha_{0}$ and deterministic trend $\alpha_{1} t$ are added to equation (3). In all equations, if the number of augmenting lags (p) is known, the augmented test is identical to the simple Dickey-Fuller test. In case the $\mathrm{p}$ is unknown, we determine it by minimizing the Schwartz Bayesian information criterion or minimizing the Akaike information criterion or lags are dropped until the last lag is statistically significant.

Before running $\mathrm{ADF}$ test, the data must be inspected to figure out an appropriate regression model. In other word, we must decide if the model in equation(1) suites our data otherwise we may use either the model in equation (2) or (3).

Based on the ADF unit root test results, the stationarity is tested using the following hypothesis.

$$
H_{0}: \varphi-1=0 \text { vs } H_{1}: \varphi-1<0
$$

The $H_{0}$ means that the variable is not stationary or has an unit root and the $H_{1}$ means that the variable is stationary.

\subsection{Test of co-integration:}

Two-time series $x_{t}$ and $y_{t}$ are said to be co-integrated if they have the same order of integration and there exists a linear combination of these 
Fatine Maghrebi, Zouaoui Chikr El Mezouar, Ibrahim Almanjahie

series that is stationary. In the following regression model (Engle and Granger, 1987)

$$
y_{t}=\beta_{0}+\beta_{1} x_{t}+u_{t}
$$

$y_{t}$ and $x_{t}$ are co-integrated if they have the same order of integration and $u_{t}$ is stationary. Since the Engle and Granger co-integration is sensitive to the choice of response variables, the test may not be consistent. So, in this work we apply Johansen maximum likelihood method (Johansen, 1991), (Johansen, 1995) to obtain the number of co-integration equations:

$$
\Delta Y_{t}=\sum_{i=1}^{p-1} \Pi_{i} \Delta Y_{t-i}+\Pi_{p} Y_{t-p}+\varepsilon_{t}
$$

where $Y_{t}$ is a k-vector of integrated variables $I(1), \varepsilon_{\mathrm{t}}$ a k-vector of white noise (components are uncorrelated with mean zero and finite variance), the matrix $\Pi_{i}$ are estimated by maximum likelihood method. The number of cointegration equations is equal to the rank of the matrix $\Pi_{p}$.

\subsection{Test of causality:}

To explore the causal relationship between oil price $O I L_{t}$ and economic growth $G D P_{t}$, we use the following model:

$$
\left\{\begin{array}{l}
\Delta O I L_{t}=\sum \alpha_{i} \Delta G D P_{t-i}+\sum \beta_{i} \Delta O I L_{t-i}+\varepsilon_{1 t} \\
\triangle G D P_{t}=\sum \lambda_{i} \Delta G D P_{t-i}+\sum \gamma_{i} \Delta O I L_{t-i}+\varepsilon_{2 t}
\end{array}\right.
$$

$\varepsilon_{1 \mathrm{t}}$ and $\varepsilon_{2 \mathrm{t}}$ are white noise error terms, uncorrelated with mean zero and finite variances. The test of causality is then performed using the following hypothesis.

- $\quad H_{0}: \alpha_{i}=0$ i.e GDP does not cause OIL.

- $H_{0}: \gamma_{i}=0$ i.e OIL does not cause GDP. 


\section{Data Analysis and Results 4.1 Stationarity of oil price and GDP:}

From Figure1, we can see that the behaviour of each series is not fluctuating around zero. The mean values of the OIL and GDP time series are trended with constant then we the test of stationarity based on equation (3) respectively. Also, it appears, from Figures2 and 3, that the difference of time series of each variable has not a trend, and so we conclude that the time series of difference GDP has a constant mean and non-trend then ADF test based on equation 2, and the time series of difference OIL has a nonconstant mean and non-trend then $\mathrm{ADF}$ test based on equation 1 . we get the results shown in Table 1.

Table 1: ADF Unit root test

\begin{tabular}{|c|c|c|c|c|c|c|}
\hline \multirow[t]{2}{*}{ Variable } & \multirow[t]{2}{*}{ Test } & \multirow[t]{2}{*}{ Lags } & \multirow{2}{*}{$\begin{array}{l}\text { Statistic } \\
\text { value }\end{array}$} & \multicolumn{2}{|c|}{ Critical value } & \multirow[t]{2}{*}{ Result } \\
\hline & & & & $1 \%$ & $5 \%$ & \\
\hline OIL & & 0 & -2.7044 & -4.6678 & -3.7332 & $\begin{array}{c}\text { Not } \\
\text { stationary }\end{array}$ \\
\hline$\Delta \mathrm{OIL}$ & $\mathrm{ADF}$ & 0 & -4.3477 & -3.9591 & -3.0810 & Stationary \\
\hline GDP & & 1 & -3.1966 & -4.7283 & -3.7597 & $\begin{array}{c}\text { Not } \\
\text { stationary }\end{array}$ \\
\hline$\Delta \mathrm{GDP}$ & $\mathrm{ADF}$ & 1 & -3.9499 & -2.7282 & -1.9662 & Stationary \\
\hline
\end{tabular}

Results in Table 1 show that the absolute values of the ADF (Statistic value) for the $O I L$ and GDP variables are smaller than the tabular absolute values at the levels of significance $1 \%$ and5\%. Therefore, we cannot reject the null hypothesis

$$
\mathrm{H}_{0}: \phi-1=0
$$

which means that the unit root is presented in each variable. In other words, the results give that the two variables are not stationary. However, the first difference for each series of each variable is stationary since the absolute values of the $\mathrm{ADF}$ (Statistic value) for the $\triangle O I L$ and $\triangle G D P$ variables are bigger than the tabular absolute values at the levels of significance $1 \%$ and 
Fatine Maghrebi, Zouaoui Chikr El Mezouar, Ibrahim Almanjahie

$5 \%$. This result gives that the oil price and the GDP have the same order of integration $\mathrm{I}(1)$.

\subsection{Cointegration equations:}

We use the Johansen test for determining the relationship between the two variables ([?]? ? ? ? ? ? in Table 2.

Table 2: Co-integration rank test

\begin{tabular}{|c|c|c|c|c|c|}
\hline $\begin{array}{c}\text { Null } \\
\text { Hypothesis }\end{array}$ & $\begin{array}{c}\text { Alternative } \\
\text { Hypothesis }\end{array}$ & Eigenvalue & Trace Statistic & $\begin{array}{c}\text { Critical value } \\
5 \%\end{array}$ & Prob. \\
\hline $\mathrm{r}=0$ & $\mathrm{r}=1$ & 0.623927 & 26.53965 & 20.26184 & 0.0059 \\
\hline $\mathrm{r} \leq 1$ & $\mathrm{r}=2$ & 0.493766 & 10.89211 & 9.164546 & 0.0233 \\
\hline
\end{tabular}

Table 2 illustrates the results of the computed Trace Statistic value, which is compared greeter than the critical value at 5\% significant level and strongly suggests the existence of the long-run relationship between the variables in the estimated model. The computed Trace Statistic value suggests that the gross domestic product and the oil prices have a long-run co-integration, where both variables move together. Hence, we conclude that there exists two cointegration equations between the two variables.

Table 3: Estimation of co-integration equations

\begin{tabular}{|c|c|c|}
\hline Oil & GDP & C \\
\hline-0.121014 & 0.143618 & -3.250891 \\
\hline-0.244148 & 0.285427 & -8.476169 \\
\hline
\end{tabular}


Test of Causality between Oil Prices and GDP. Case Study Saudi Arabia

Unrestricted Cointegrating Coefficients (normalized by $b^{\prime * S} 11^{*} \mathrm{~b}=\mathrm{I}$ )

The equations are writing as:

$$
\begin{aligned}
& -0.121014 * \mathrm{OIL}=0.143618 * \mathrm{GDP}-3.250891 \\
& -0.244148 * \mathrm{OIL}=0.285427 * \mathrm{GDP}-8.476169
\end{aligned}
$$

\subsection{Granger causality tests results:}

Granger causality test is valid for variables that do not have cointegrating relationship. In this paper, there are two pairs of variable that are suited for employing this test, namely oil price and GDP. After applying Granger causality test we find result bellow:

Table 4: Granger Causality test

\begin{tabular}{|c|c|c|c|}
\hline Null Hypothesis & Observations & F-Statistic & Prob. \\
\hline GDP does not cause OIL & \multirow{2}{*}{16} & 11.6298 & 0.0046 \\
\cline { 1 - 2 } & \multirow{2}{*}{ OIL does not cause GDP } & 9.93583 & 0.0076 \\
\hline
\end{tabular}

The null hypothesis that GDP does not Granger Cause oil price can be rejected at $1 \%$ significant level. The null hypothesis that oil price does not Granger Cause GDP can be rejected at $1 \%$ significant level. These results indicate that there is a bidirectional Granger causality between the GDP and oil price. Oil price is the Granger cause of economic growth. Meanwhile Saudian's economic growth is also the Granger cause of the oil price.

\section{Conclusion:}

The main object of this study is to investigate the real relationships between oil price and the real gross domestic product in Saudi Arabia based on a real data from 1998 to 2014.This paper arrives at the following three conclusions by employing co-integration theory and Granger causality test. First, we analysis the data series characteristics using ADF test, and as a result we reject the hypothesis of non-stationarity at first difference for both series. Secondly, we run the Johansen co-integration rank test and found that there are two co-integration relationships between oil prices and GDP.

DOI: 10.24818/18423264/52.3.18.19 
Fatine Maghrebi, Zouaoui Chikr El Mezouar, Ibrahim Almanjahie

Finally, by using the Granger causality test, we concluded that there is a bidirectional Granger causality between the GDP and oil price.

ACKNOWLEDGEMENTS:

The authors extend their appreciation to the Deanship of Scientific Research at King Khalid University for funding this work through research groups program under grant number (R.G.P-51-38).

\section{REFERENCES}

[1] Abosedra, S., Baghestani, H. (1991), New Evidence on the Causal Relationship between United States Energy Consumption and Gross National Product; Journal of Energy Development. 14(2), 285-292;

[2] Altinay, G., Karagol, E. (2004), Structural Break, Unit Root, and the Causality between Energy Consumption and GDP in Turkey; Energy Econ. 26, 985-994;

[3] Amaira, B. (2012), The Relationship of Oil Prices and Economic Growth in Tunisia: A Vector Error Correction Model Analysis; The Romanian Economic Journal 43, 3-22;

[4] Dickey, D.A., Fuller, W.A. (1996), Distribution of the Estimators for Autoregressive Time Series with a Unit Root; Journal of the American Statistical Association, 74, 427-431;

[5] Dickey, D.A., Fuller, W.A. (1981), Likelihood Ratio Statistics for Autoregressive Time Series with a Unit Root; Econometrica, 49, 1057-1072;

[6] Elmezouar, Z. C., Mazri, A.Benzaire, M., Boudi, A.E.K. (2014), Test of Causality between Oil Price and GDP Growth in Algeria; Advances in Applied Mathematics, Springer Proceedings in Mathematics \& Statistics 87, 205-213;

[7] Engle, R.F., Granger, C.W.J. (1987), Cointegration and Error Correction: Representation, Estimation, and Testing; Econometrica 55(2), 251-76;

[8] Federer, J. (1996), Oil Price Volatility and the Macro-Economy; Journal of Macroeconomics, 18, 1-26;

[9] Gounder, R., Bartleet, M. (2007), Oil Price Shocks and Economic Growth: Evidence for New-Zeland, 1989-2006; Paper presented at the New Zealand Association of Economist Annual Conference, Christchurch, 27th to 29 June; [10] Granger, C.W.J. (1969), Investigating Causal Relations by Econometric Models and Cross Spectral Methods; Econometrica 36, 424-438;

[11] Granger, C.W.J. (1988), Some Recent Developments in a Concept of Causality; Journal of Econometrics 39, 199-211;

[12] Hamilton, J.D. (1983), Oil and the Macro-economy since World War II; Journal of Political Economy 91, 228-248; 
Test of Causality between Oil Prices and GDP. Case Study Saudi Arabia

[13] Hamilton, J.D. (1996), This is What Happened to the Oil Price-MacroEconomy Relationship; Journal of Monetary Economics 38, 215-220;

[14] Hamilton, J.D. (1997), Supply Shocks; In D. Glasner and T.F. Cooley Eds., Business cycles and depressions: An Encyclopaedia, 670-672. New York: Garland;

[15] Hooker, M.A. (1996a), What Happened to the Oil Price-Macro-Economy Relationship?; Journal of Monetary Economics 38, 195-213;

[16] Jin, Guo (2008), The Impact of Oil Price Shock and Exchange Rate Volatility on Economic Growth: A Comparative Analysis of Russia Japan and China; Research Journal of International Studies, 8, 98-111;

[17] Johansen, S. (1991), Estimating and Testing of Co-Integration Vectors in Gaussian Vector Autoregressive Models; Econometrica 59, 1551-1581;

[18]Johansen, S. (1995), Likelihood Based Inference in Co-Integration Vector Autoregressive Models; Oxford University Press, Oxford 1995a;

[19] Lee, K., Ni, S., Ratti, R.A. (1995), Oil Shocks and the Macro-Economy:

The role of Price Variability; Energy Journal, 16, 39-56;

[20] Lee, K., Ni, S. (2002), On the Dynamic Effects of Oil Price Shocks: A Study

Using Industry Level Data; Journal of Monetary Economics 49, 823-852;

[21] Mork, K.A. (1989), Oil and the Macro-Economy When Prices Go Up and

Down: An extension of Hamilton Results; Journal of Political Economy, Vol. 97, No. 3, 740-744;

[22] Saudi Arabian Monetary Authority (2016); Saudi Arabia, accessed 1

February 2017, http://www.sama.gov.sa/en-

US/EconomicReports/Pages/YearlyStatistics.aspx.

DOI: $10.24818 / 18423264 / 52.3 .18 .19$ 